\title{
Coil Pump Design for a Community Fountain in Zambia
}

\author{
Phillip L. Thompson \\ Department of Civil \& Environmental Engineering \\ Seattle University \\ Seattle, WA 98122 \\ thompson@seattleu.edu \\ Sonya Milonova \\ Department of Natural Resources and Parks \\ King County \\ Seattle, WA 98105 \\ sonya.milonova@gmail.com \\ Meghan Reha \\ DNV Renewables (USA) Inc. \\ Seattle, WA 98101 \\ meghan.reha@dnv.com \\ Faisal Mased \\ Department of Civil \& Environmental Engineering \\ Washington State University \\ Pullman, WA 99164 \\ faisalmased@gmail.com \\ Ian Tromble \\ Union Pacific Railroad \\ Seattle, WA 98108 \\ iantheflyingsquirrel@gmail.com
}

\begin{abstract}
The municipal water distribution system in Chirundu, Zambia is not affordable for many residents, so most families collect water, wash their clothes and socialize along the banks of the Zambezi River. The river is the native habitat for the Nile crocodile, and several fatal attacks have occurred at this site. Using locally available materials, a team of engineering students from Seattle University designed a waterwheel and coil pump to provide 30 liters of water per minute to a safe gathering area $\mathbf{3 0}$ meters onshore and at an elevation of 10 meters above the river. The team also sized a water storage system and designed a series of washbasins for the site. Local residents were able to improve the design and construction of the pump, and it has performed for up to two months without maintenance. The coil pump has the potential to provide crop irrigation for many neighboring communities. For this to be a sustainable technology, the pump's rotating joint must be carefully fabricated.
\end{abstract}

Index Terms - coil pump, waterwheel, irrigation, water supply 


\section{INTRODUCTION}

By 2025, it is predicted that over 5 billion people or two-thirds of the planet will be affected by moderate to severe water shortages ${ }^{1}$. These shortages will be caused by both climate change and human population growth and will result in more people walking greater distances to meet their daily water needs. This increased burden will disproportionately fall to women and girls who are typically responsible for collecting water for their families and who already spend an average of three hours per day on this laborious task ${ }^{2}$. Water shortages will also mean greater stresses on agriculture producers who currently use approximately 70 percent of all available freshwater for irrigating crops and animals ${ }^{3}$.

Poor rural communities in the developing world who already struggle during periods of drought will continue to be challenged to meet their water needs in the years to come. One such community is the town of Chirundu, Zambia which has a population of approximately 7000 people and is located on the Zambezi River. During the three-month dry season, farmers in Chirundu irrigate their crops with bucket brigades between the Zambezi and their fields. This task has the added threat of crocodiles that inhabit the shallow waters along the riverbank ${ }^{4}$. In 2008 alone, four Chirundu residents were killed by crocodile attack.

In August 2008, Father Michele Crugnola who is a parish priest in Chirundu contacted the Seattle University Engineering Project Center (Seattle, Washington, USA) to help design and build a pump that could sustainably deliver water to safe onshore gathering places and to agricultural fields. Two civil engineering and two mechanical engineering students were selected to work on the project for their year-long engineering senior design capstone course. To meet the criterion of sustainability, the pump needed to be inexpensive, powered by the river and easily maintained by the residents. The pump was also expected to serve up to 200 people per day. According to the World Health Organization (WHO), an individual requires approximately 20-L per day for basic health and hygiene needs (drinking, cooking, bathing and washing clothes) ${ }^{5}$, but we assumed 50-L per day for a community water demand of 10,000 L/day or $7.2 \mathrm{~L} / \mathrm{min}$. These design criteria are summarized in Table 1.

The Kariba Dam controls the water level of the Zambezi River so that there is approximately a 3-m differential between the seasonal high and low-water levels ${ }^{6}$. This elevation difference, along with the location and height of the storage tanks, provided a total head requirement for the pumping system of $10-\mathrm{m}$. The river velocity was assumed to average $1 \mathrm{~m} / \mathrm{s}$ based on anecdotal observations $^{6}$. Pumped water would be stored and then piped to a fountain as shown in Figure 1.

TABLE I

SUMMARY OF PUMP DESIGN CRITERIA

1. Powered by the Zambezi River

2. Flow rate of 10,000 liters per day

3. Minimum of 10 meters of pumping head

4. Made from local materials

5. Easily maintained by locally available labor 


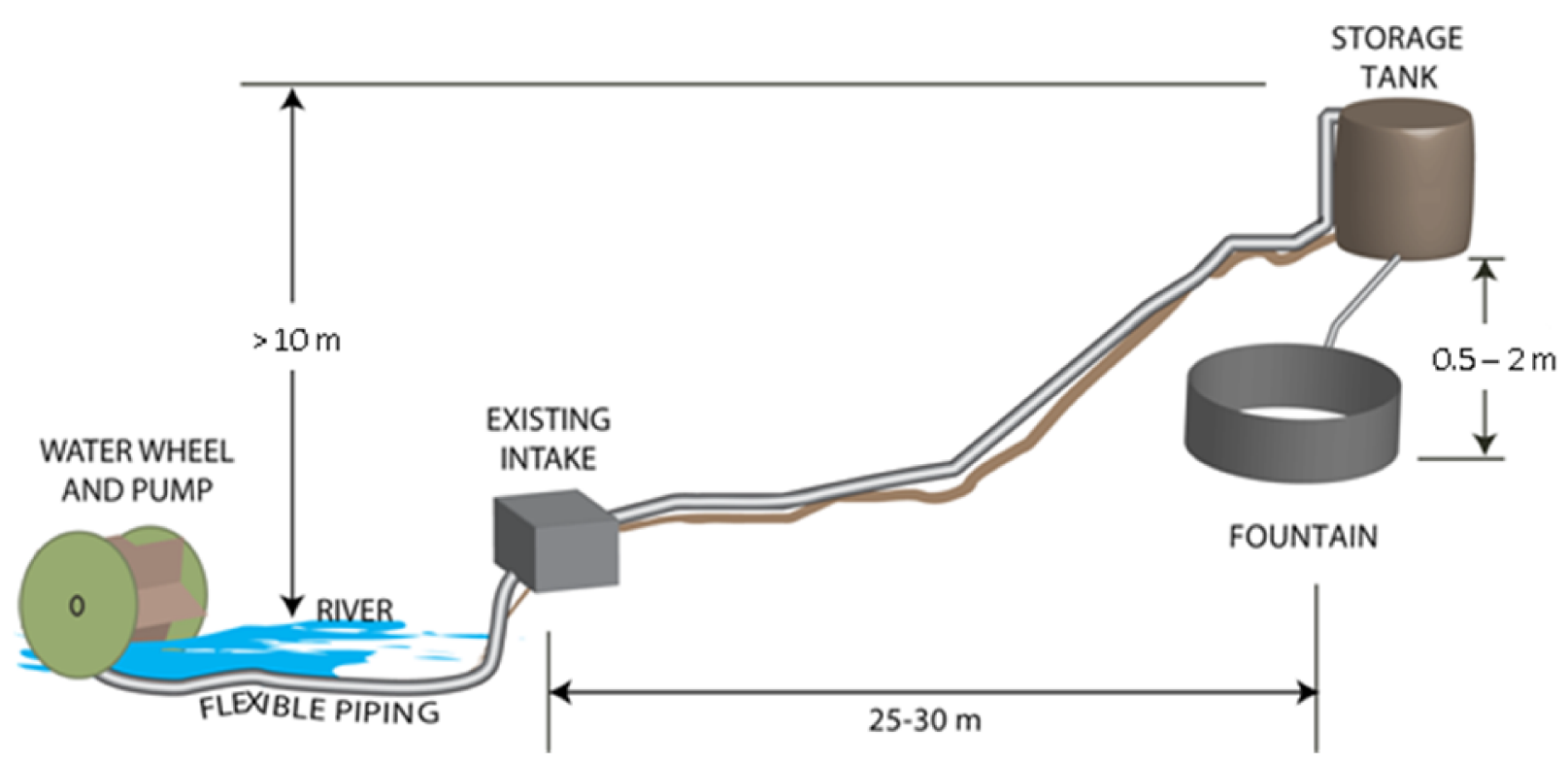

FIGURE 1

CONCEPTUAL DESIGN FOR THE RIVER-POWERED WATER SUPPLY SYSTEM

\section{DESIGN AND CONSTRUCTION}

\section{Pump Selection}

To use the Zambezi River as a power source, the team first considered a micro-hydroelectric generator (MHG) to directly power a centrifugal pump. Centrifugal pumps are mechanically simple, require little maintenance and are relatively inexpensive. For approximately \$200 a 250W centrifugal pump can provide a flow rate of approximately $40 \mathrm{~L} / \mathrm{min}$ at 6-m of head. However MHGs are expensive, ranging from \$3,000-\$30,000 USD and difficult to maintain ${ }^{7}$. Given the life-cycle costs and skilled-labor requirements for maintenance, the team decided that MHG was not an acceptable alternative for this site.

The team also considered generating pumping power by connecting a waterwheel to a centrifugal pump. To do so, the rotational motion of the waterwheel must match the recommended impeller speed. Most pump impellers are designed to rotate at a constant speed between 900 and 3600 revolutions per minute (rpm), while waterwheels typically rotate in the 1$10 \mathrm{rpm}$ range $^{8}$. Since transmitting the torque from a slow-moving waterwheel to adequately drive a centrifugal pump would require minimum gear-ratios approaching 100:1 and relatively expensive drive-components that would be difficult to locally reproduce, this alternative was not pursued.

The option of using a hydraulic ram pump (HRP) was also considered. HRPs use the energy of falling water to power the pump, have few moving parts and are inexpensive to build and operate $^{9}$. For an HRP to work effectively, there must be a significant head difference between the elevation of the water source and the pump. An HRP with a head difference or working fall of three meters has been estimated ${ }^{9}$ to deliver a flow rate of $260 \mathrm{~L} / \mathrm{d}$ at a head of $10-\mathrm{m}$. The HRP option was not suitable for this project because the source water elevation was not significantly 
higher than the pumping site and HRP flow rates were not expected to meet the required 10,000 L/d water demand.

A fourth option involved using a coil pump which is closely related to Archimedes' snail pump where a tube is wrapped around a pole that is rotating on an inclined axis. The first version of the coil pump has been attributed to Andrew Wirtz (c. 1749) ${ }^{10,11}$. The modern day version of the coil pump (also known as the spiral pump, hydrostatic pump or manometric pump) was invented by Belcher in $1972^{12}$ and independently produced by others ${ }^{13,14,15}$. The coil pump is a positive displacement pump that uses rotational motion to create a cumulative pressure wave to deliver water. It consists of a pipe coiled along one plane and fixed onto a rotating horizontal shaft, such as the axle of a waterwheel. Each coil is wound along the circular mount where the next coil is smaller in diameter than the previous one (Figure 2).

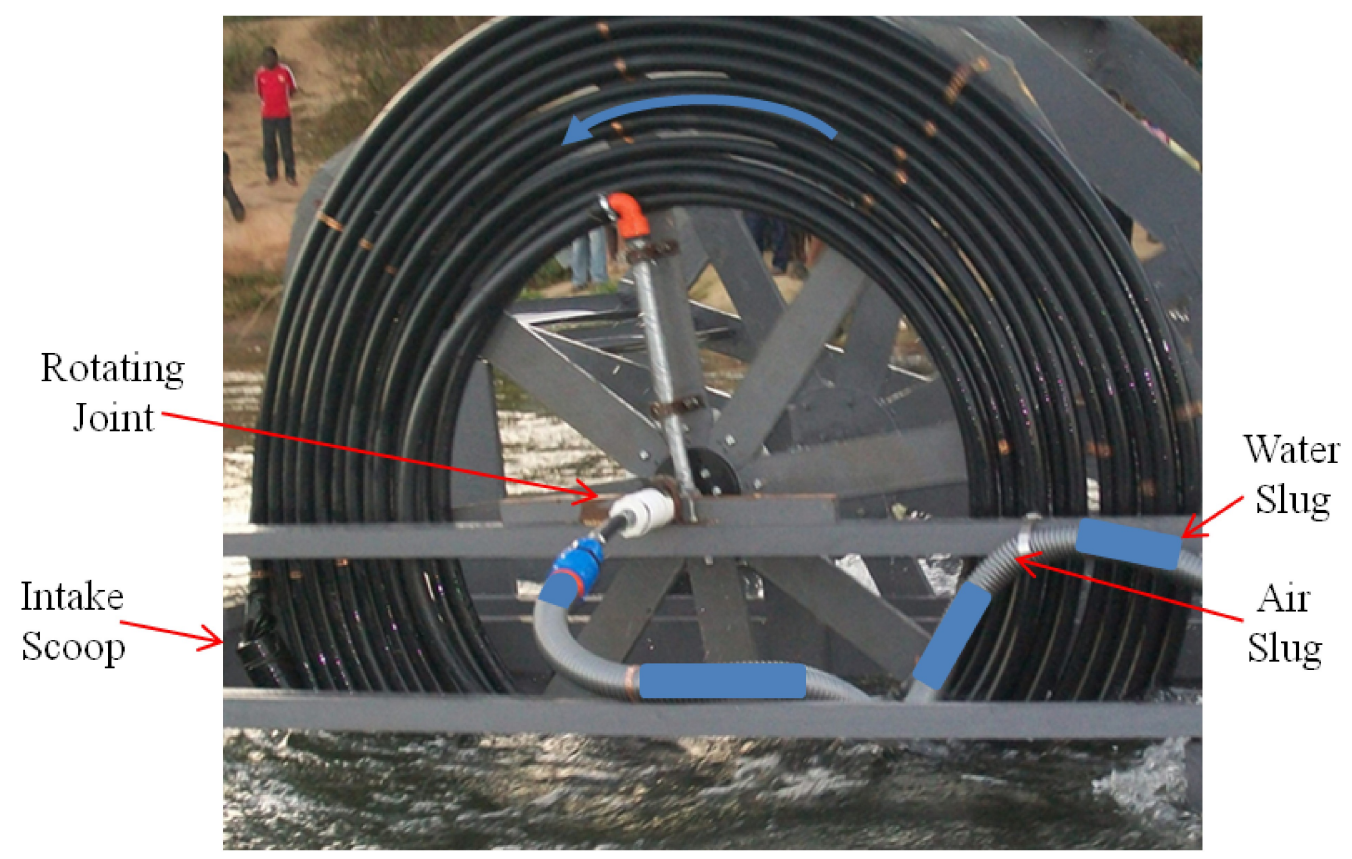

FIGURE 2

COMPRESSED SLUGS OF AIR PROVIDE A CUMULATIVE PRESSURE-HEAD FOR THE COIL PUMP.

With each revolution of the pump, alternating slugs of water and air are forced into the pipe. As the wheel spins it compresses the air in the pipe and creates a pressure head within each coil. A cumulative head is built-up at the inner coil and water is forced out the delivery pipe. The pump intake scoop is typically made from a larger diameter pipe and can be used to vary the amount of water taken in with each revolution. According to Tailer ${ }^{16}$, the scoop should be approximately half the volume of the outer coil and should be enclosed in wire mesh to prevent debris from entering the coils. 
Mortimer and Annable ${ }^{17}$ developed a theory that successfully predicted the pump discharge (Equation 1) and pressure head (Equation 2) for a stream-powered coil pump.

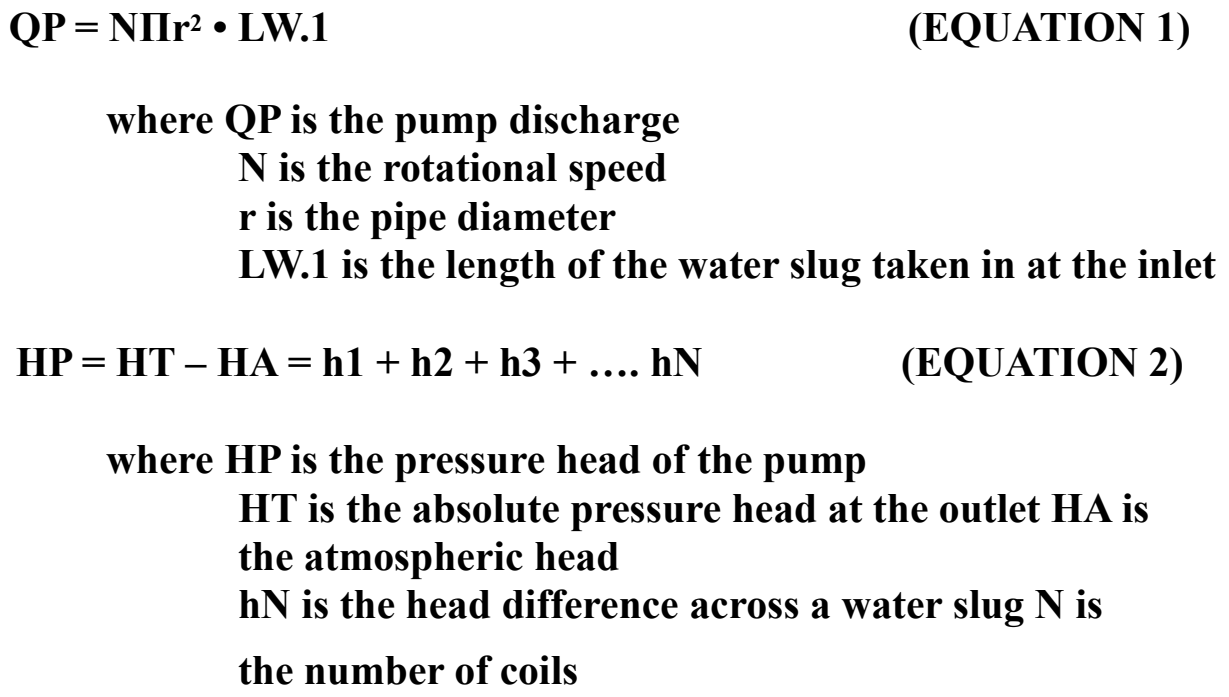

More recently, Kassab et al. ${ }^{18}$ evaluated the performance of a coil pump by varying the number of coils, the submerged ratio ( $\mathrm{S} \mathrm{r}$ ) and the rotational speed of the pump $(\mathrm{N})$. They found that 1) increasing the number of coils increased the pressure head (HP) while the discharge (QP) remained constant, 2) as the Sr approached 100 percent, QP increased but there is no significant effect on HP and 3) increasing $\mathrm{N}$ had negligible effects on HP but increased QP to Qmax (for any given Sr) after which the amount of air entering the system began to decrease and QP approached zero.

\section{Seattle Prototype Construction and Testing}

For the first prototype, a 4-ft diameter industrial cable spool served as the sides of the waterwheel ${ }^{19}$. The inner slats of the spool were removed and the sides were re-connected with an 8 -ft rod of $1 \frac{1}{4}$ in diameter made of 1018 cold-rolled mild steel. The shaft was mounted with two $1 \frac{1}{4}$ in pillow stainless steel block bearings with a thermoplastic case. The twelve blades of the waterwheel were made by cutting $6 \times 8 \mathrm{ft}$ sheets of roof sheathing into $3-\mathrm{ft} \times 1.5$ - $\mathrm{ft}$ rectangles and were attached to the sides of the waterwheel using twenty $1 \frac{1 / 4}{4}$-in by $1 / 8$-in angle iron brackets. These also provided rigidity and strength to the center of the waterwheel. All waterwheel parts were attached with Grade 2 zinc-plated bolts. The waterwheel's float platform was a 2-ft x 4-ft wooden frame attached to four 30-gallon plastic drums.

The prototype waterwheel was tested in June 2009 at the South Park Marina on the Duwamish River in Seattle, WA, in a location that is near enough to the ocean to be affected by the tides. The purpose was to test at slack tide, push the waterwheel with a powerboat at speeds near $1 \mathrm{~m} / \mathrm{s}$ and measure the waterwheel's rotational speed in revolutions per minute (rpm). A 
Garmin GPS tracker (Garmin International Inc., Olathe, KS) was used to measure overland speed and a Swoffer velocity meter (Swoffer Instruments Inc., Seattle, WA) was used to measure the velocity of the waterwheel relative to the river. Under these conditions, the wheel rotated at 4-5 rpm. After observing the performance of the waterwheel the team made design revisions that included 1) adding curved PVC plastic blades to reduce the volume of water weighing down the blades as they exit the water and 2) adding a collar to prevent axial slip of the waterwheel. The prototype testing also confirmed the team's theoretical buoyancy calculations and floating platform design.

With the revisions in mind, a second waterwheel was constructed and was connected to the coil pump (10 coils of 1 -in flexible PVC pipe) and to the floating platform to achieve a blade submergence of 30 percent (Figure 3). The coil pump was able to produce $10 \mathrm{~L} / \mathrm{min}$ at $5 \mathrm{rpm}$. The total cost of the 400-lb Seattle prototype was approximately \$800 US.

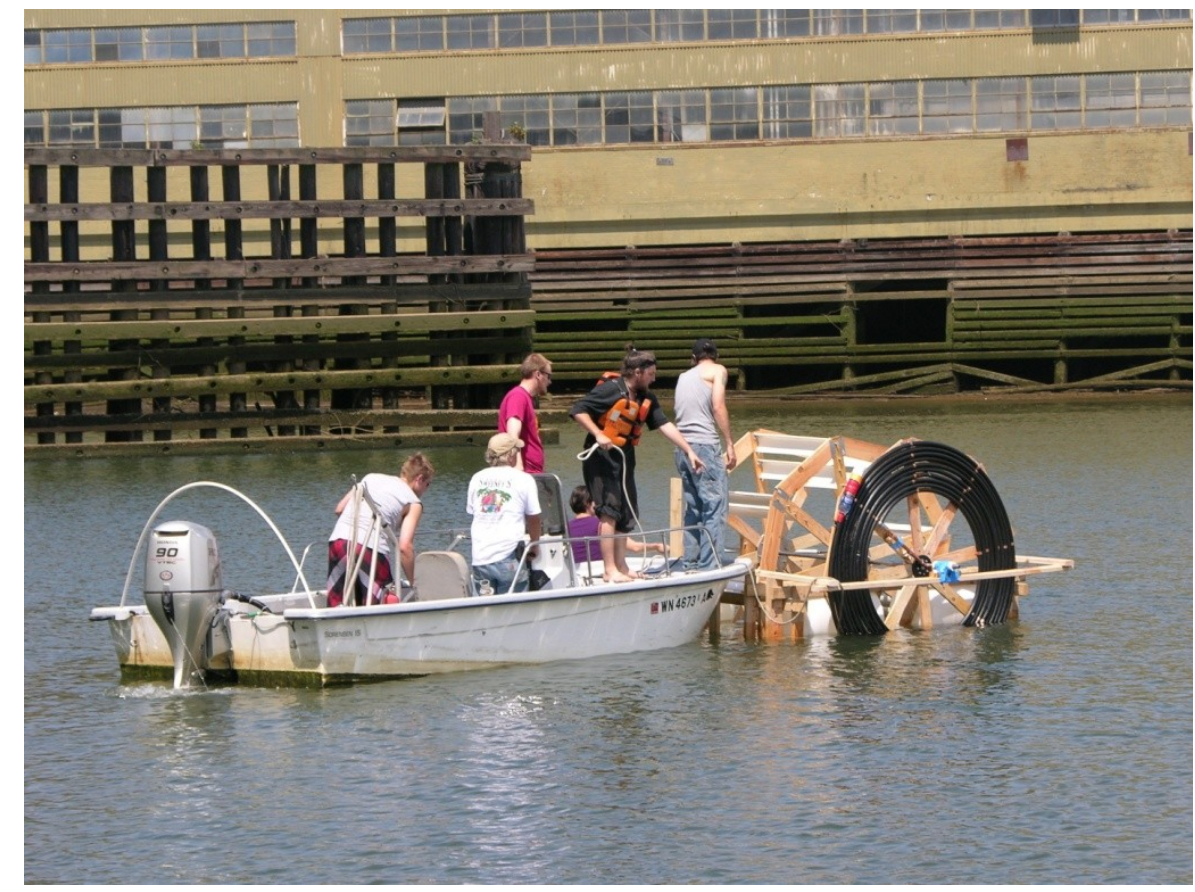

FIGURE 3

THE PROOF-OF-CONCEPT COIL PUMP WAS TESTED ON THE DUWAMISH RIVER IN SEATTLE, WA.

\section{Zambia Prototype Construction and Testing}

In July 2009, the Seattle University team traveled to Chirundu to test their design. The team received a warm welcome from Father Crugnola and members of the local church parish. Residents in the community were very engaged in the process and made contributions ranging from welding expertise to finding local materials. The first coil pump built in Chirundu (Figure 4) was constructed of wood and coated with several layers of water-proof paint. The axle was the same 8-ft rolled steel shaft that was used in the Seattle waterwheel, and the paddles were made with pieces of PVC. Four 55-gallon drums were used for the floating platform, and the twelve coils of pipe were made of flexible 1-in PVC. The pump's 20-ft anchor was made by filling one- 
third of a 55-gallon metal drum with concrete. The anchor chain was fabricated by welding 1.25$\mathrm{cm}$ rebar segments. The 350-pound anchor was rolled onto a boat and dropped approximately 20-m upstream from the coil pump’s location. The total materials cost was approximately \$2000 US.

The first Zambia coil pump was able to deliver $30 \mathrm{~L} / \mathrm{min}$ at a head of approximately 12-m. Three days after the student team returned to Seattle, the screws of the floating platform came loose and the pump failed. It became clear that the materials (e,g, wood, set screws, plastic discs) were not strong enough to withstand the Zambezi River environment. In addition, the one-sided design (with the coil pump outside the pontoon) caused the pump to wobble, and the pulsing of the water caused additional wear on the pipe fittings, weakening them.

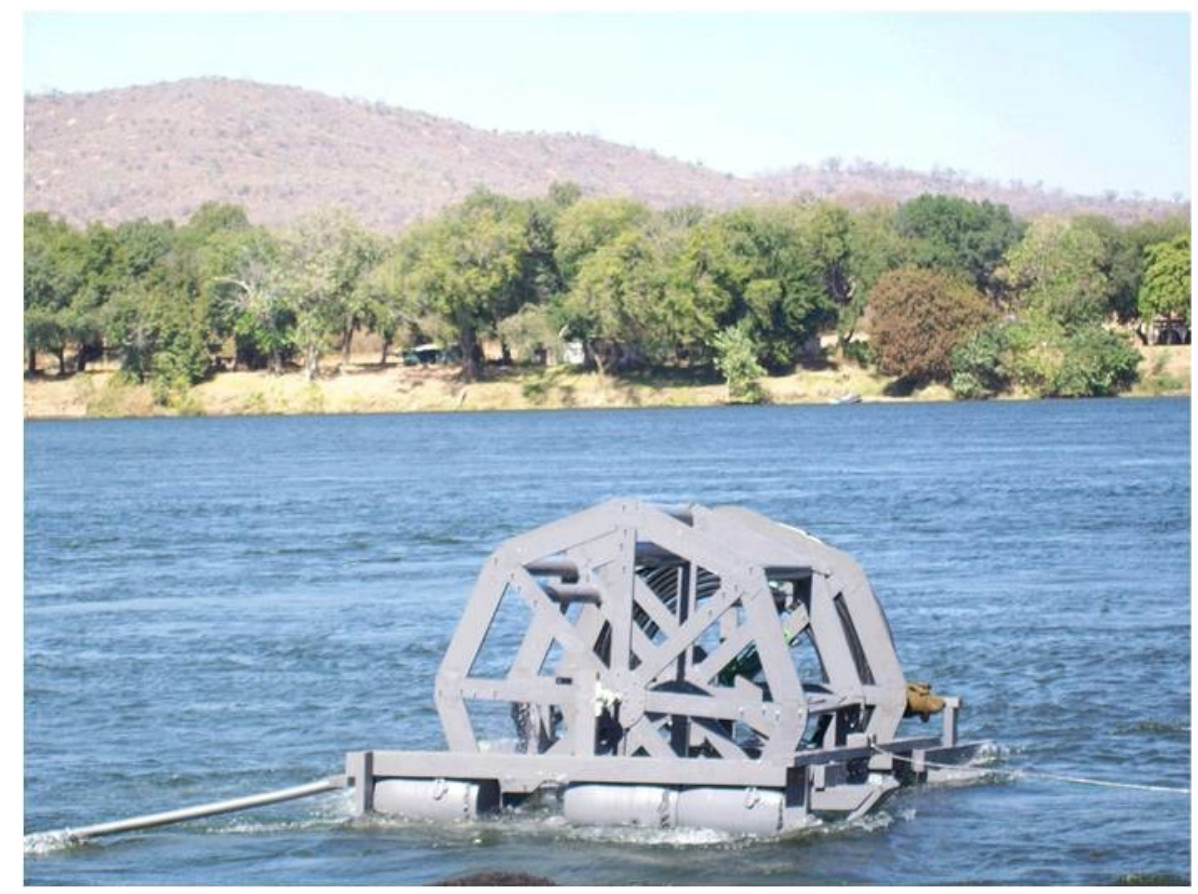

FIGURE 4

TESTING OF THE FIRST COIL PUMP IN CHIRUNDU, ZAMBIA

The community leader, Father Michele Crugnola and his team proceeded to work on a new version of the pump that re-used the wheel and shaft and included hydrodynamic pontoons made entirely of $1.2 \mathrm{~mm}$ thick steel (Figure 5).After one week of operating the second pump, the bolts connecting the waterwheel and the floating platform sheared and the pump broke apart. This may have been partially due to debris build-up along the anchor chain. At this point the residents decided to make the entire pump out of welded 2-cm square galvanized iron pipes with 1.2-mm galvanized iron paddles. The third version of the pump (Figure 6) also utilized a 5-cm diameter galvanized iron pipe for the wheel axle. To improve balance and increase the pump discharge, each side of the wheel had 13 coils of 1-in PVC pipe. At $7 \mathrm{rpm}$, this third version of the pump was able to pump approximately $36 \mathrm{~L} / \mathrm{min}$ to 6500-L storage tanks located approximately 10-m above the river surface elevation. The total cost of materials and labor were approximately \$3000 US. 


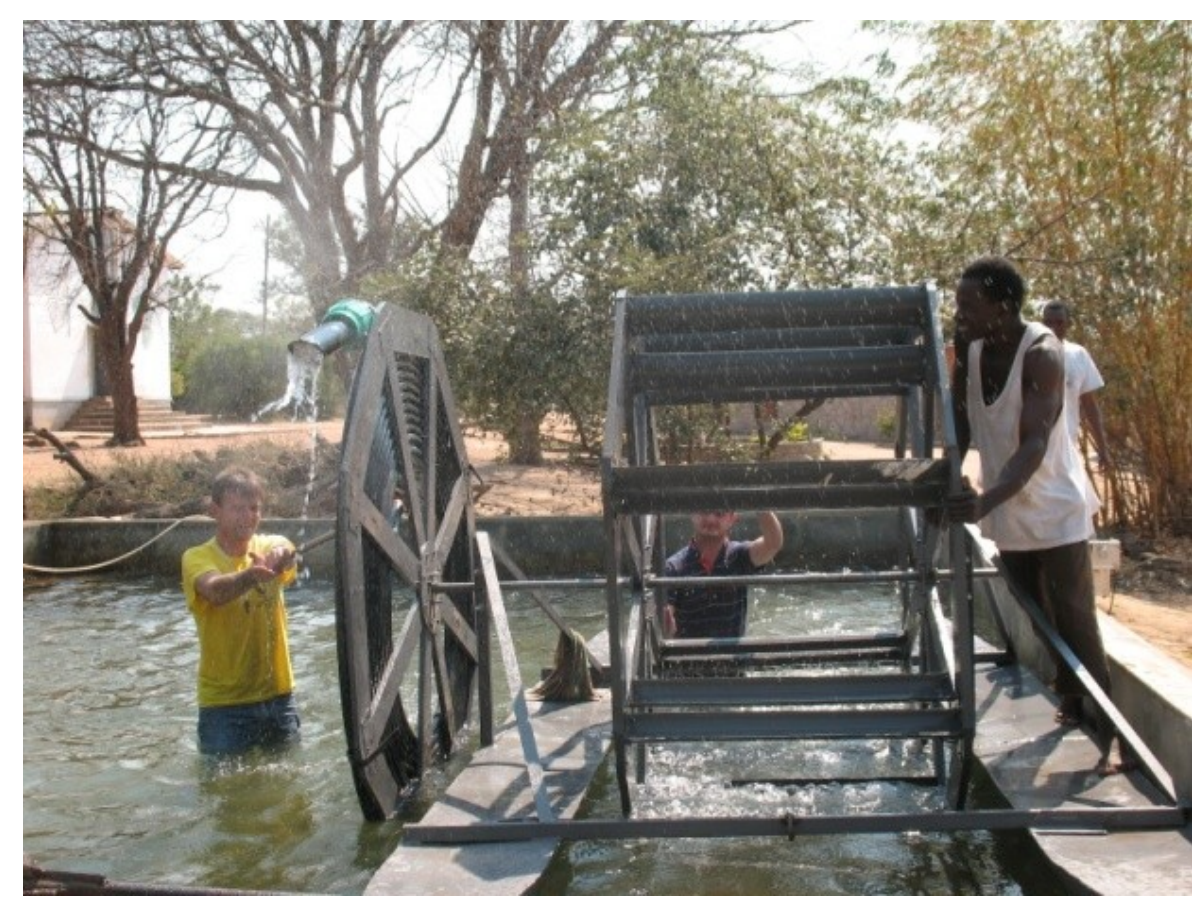

\section{FIGURE 5}

THE SECOND COIL PUMP IN CHIRUNDU WITH HYDRODYNAMIC PONTOONS

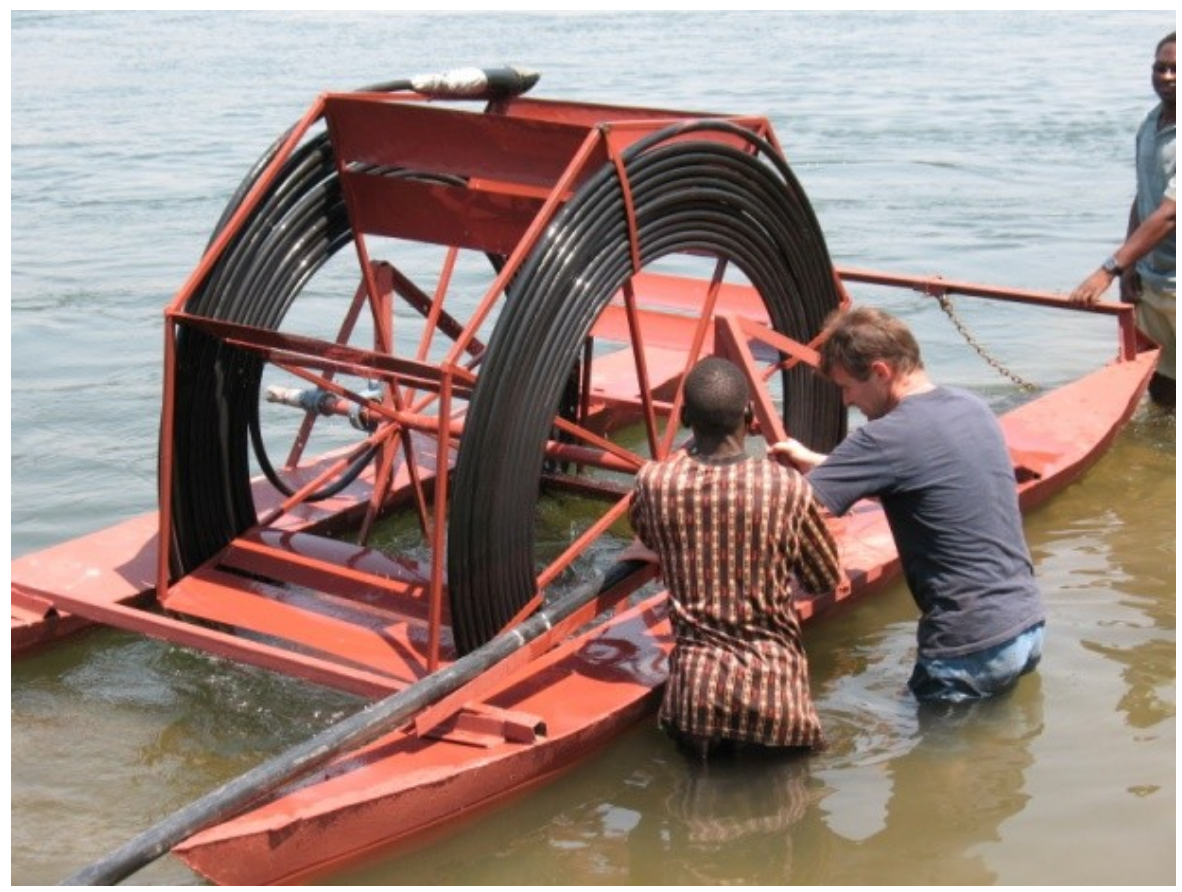

FIGURE 6

THE THIRD COIL PUMP IN CHIRUNDU WAS CONSTRUCTED ENTIRELY OF STEEL. 
After two months of continuous operation, the pump began losing pressure due to a leak at the rotating joint (Figure 7). The first version of the joint was made from PVC couplings and rubber o-rings. After replacing the o-rings, the joint lasted for approximately one month and then began leaking again. After another round of o-ring replacements, the joint only lasted three days. It was discovered that this increased wear on the joint was due to deformation of the iron axle.

In July 2010, a team of Seattle University engineering students returned to Chirundu to help troubleshoot the rotating joint problem. To re-build the joint, a piece of the 2.5-cm copper pipe was inserted into a piece of 5-cm PVC pipe. The space between the two pipes was filled with pieces of fabric and grease. The new joint was attached so that the 5-cm pipe fit around and rotated with the central shaft. The copper pipe was then connected to the stationary PVC pipe leading to the storage tanks. To date, this simple and inexpensive joint has continued to work well, and the goal is to have the joint be maintenance-free for at least a six month period. Should deformation of the axle continue to be a problem, rolled-steel axles may have to be imported.

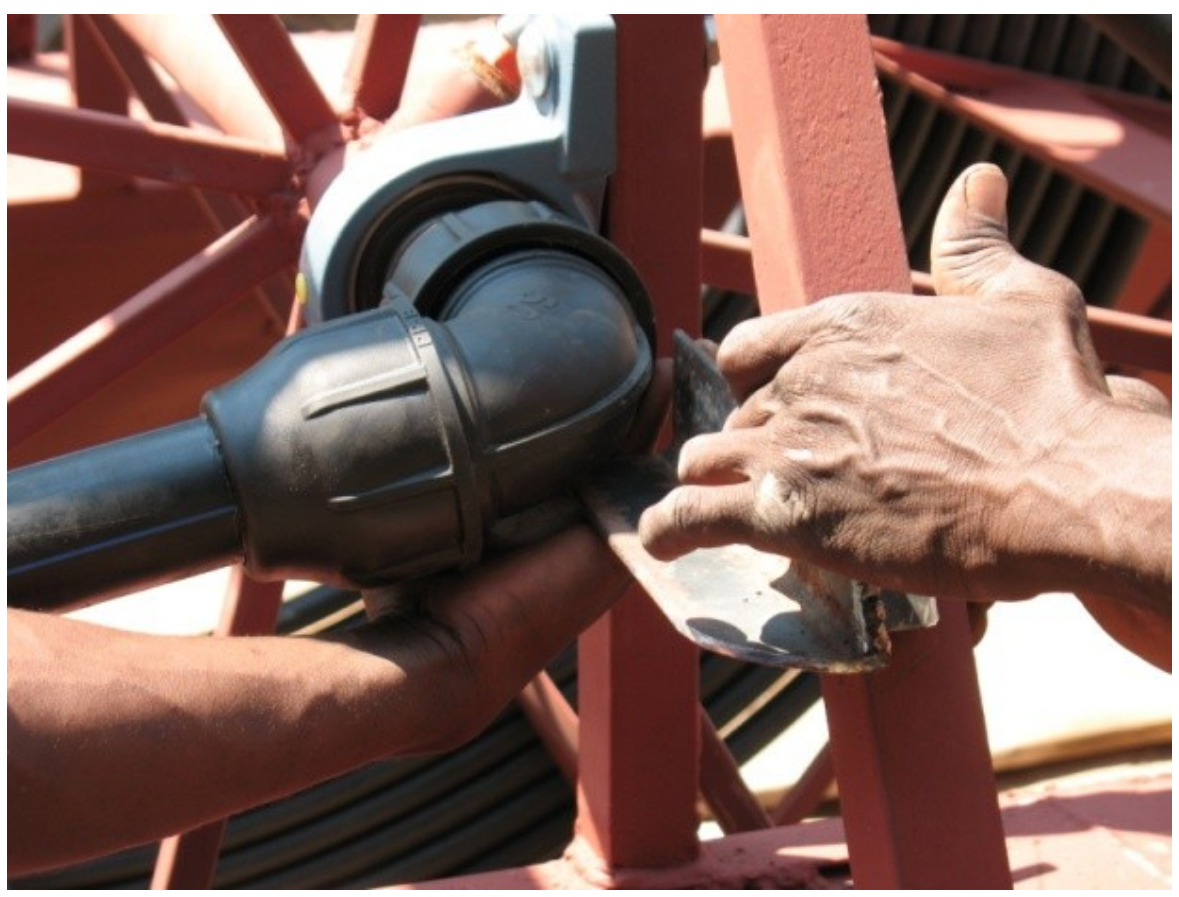

FIGURE 7

THE ROTATING JOINT FOR THE COIL PUMP CONNECTS A FIXED PIPE TO A ROTATING PIPE.

\section{Storage and Fountain Design}

To determine the required peak storage, a normal distribution for fountain use by the service population of 200 was assumed along with a 50-L per capita daily demand. Table II illustrates the demand and the change in storage throughout the day and indicates that $6000 \mathrm{~L}$ of storage can adequately meet the demand during peak hours. A 4000-L and a 2500-L water storage tank were purchased for $\$ 650$ US and were used to supply the fountain. 
To design the fountain, it was assumed that it needed to serve a maximum of 30 people at any time. It also was required to have washbasins that could be easily drained. The selected fountain design (Figure 8) consisted of four circular basins that permit one to overflow into the next. Each basin was 1-m in diameter. The first two basins were 1-m in height and the last two were $0.8 \mathrm{~m}$ high. Each four-basin structure required approximately 1,200 bricks at a cost of $\$ 400$ US. Residents from the community were responsible for the entire fountain construction process. They dug trenches for piping, made the bricks and built the wash basins.

TABLE II

A WATER STORAGE MODEL INDICATED THAT 6000-L OF STORAGE WOULD MEET THE DEMAND OF 200 USERS ASSUMING A DEMAND OF 50 LPD PER CAPITA.

\begin{tabular}{ccccc}
\hline Time & Qin & Users & Qout & $\mathbf{6 0 0 0 ~ \mathbf { ~ }}$ \\
hr & L/hr & & L/hr & Storage \\
& & & & Tank \\
\hline 1:00 AM & 432 & 0 & 0 & 3762 \\
2:00 AM & 432 & 0 & 0 & 4194 \\
3:00 AM & 432 & 0 & 0 & 4626 \\
4:00 AM & 432 & 0 & 0 & 5058 \\
5:00 AM & 432 & 0 & 0 & 5490 \\
6:00 AM & 432 & 0 & 0 & 5922 \\
7:00 AM & 432 & 2 & 100 & 6000 \\
8:00 AM & 432 & 4 & 200 & 6000 \\
9:00 AM & 432 & 11 & 550 & 6000 \\
10:00 AM & 432 & 17 & 850 & 5582 \\
11:00 AM & 432 & 24 & 1200 & 4814 \\
12:00 PM & 432 & 27 & 1350 & 3896 \\
1:00 PM & 432 & 30 & 1500 & 2828 \\
2:00 PM & 432 & 27 & 1350 & 1910 \\
3:00 PM & 432 & 24 & 1200 & 1142 \\
4:00 PM & 432 & 17 & 850 & 724 \\
5:00 PM & 432 & 11 & 550 & 606 \\
6:00 PM & 432 & 4 & 200 & 838 \\
7:00 PM & 432 & 2 & 100 & 1170 \\
8:00 PM & 432 & 0 & 0 & 1602 \\
9:00 PM & 432 & 0 & 0 & 2034 \\
10:00 PM & 432 & 0 & 0 & 2466 \\
11:00 PM & 432 & 0 & 0 & 2898 \\
12:00 AM & 432 & 0 & 0 & 3330 \\
\hline & Total & $\mathbf{2 0 0}$ & $\mathbf{1 0 0 0 0 L / d a y ~}$ & \\
\hline & & & & \\
\hline
\end{tabular}




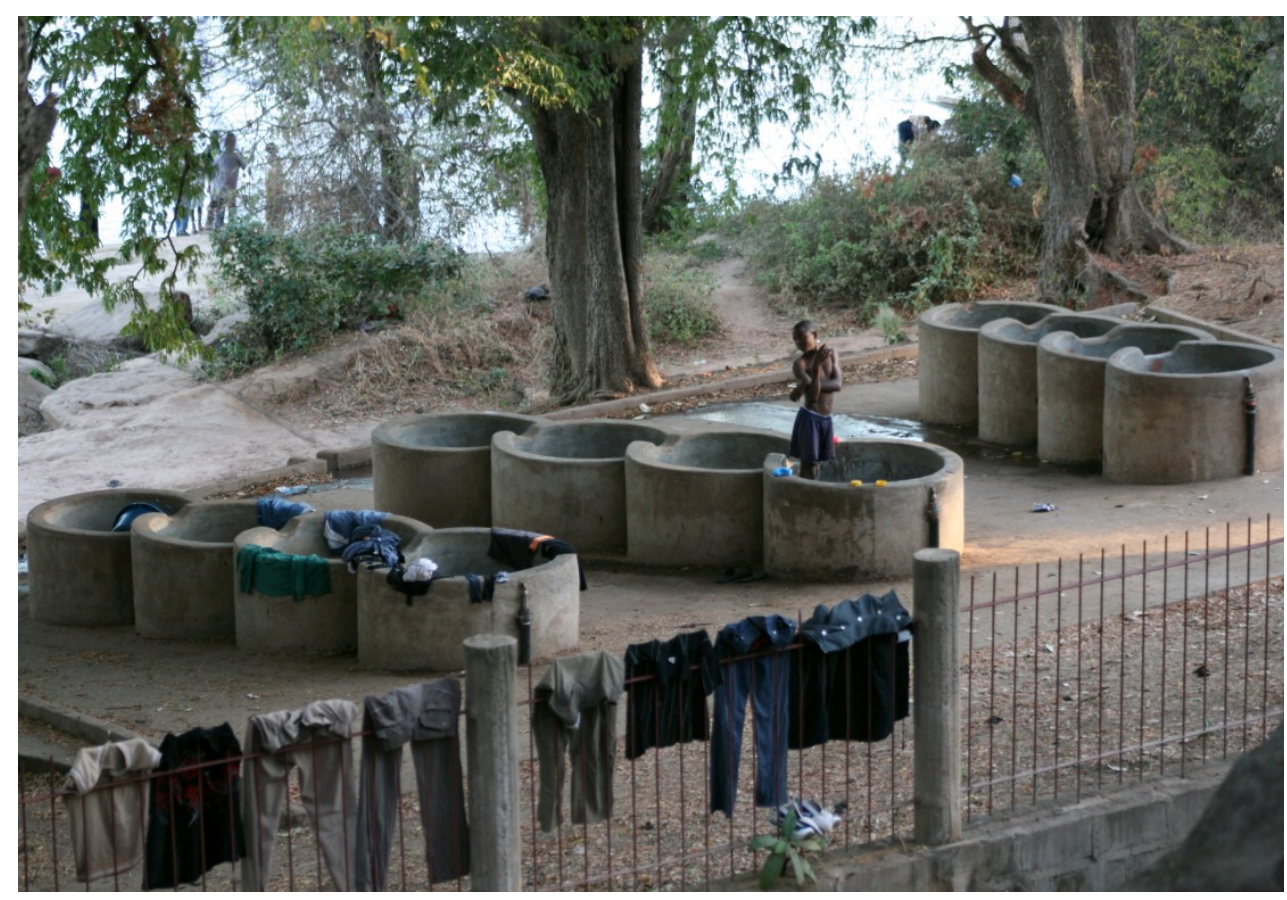

FIGURE 8

THE FOUNTAIN CONSISTS OF THREE SETS OF CASCADING WASHBASINS.

\section{CONCLUSIONS}

Today, there are still many more people using the river than are using the fountains because the demand for water by hundreds of residents exceeds what the pump can provide. As a result, there are plans to add another coil pump and construct additional basins. There have also been several requests for coil pumps by neighboring communities that are primarily interested in the pumps for the irrigation of crops during the dry season. This potential demand holds promise for the future development of a small business enterprise as well.

The coil pump was a suitable solution for the community because it could be powered by the river, made from local materials and easily maintained by the residents. The pump was also able to meet the daily water needs of up to 200 residents and was proven to be capable of delivering over $30 \mathrm{~L} / \mathrm{min}$ of water under pressure heads of up to $12-\mathrm{m}$. The $\$ 3000$ cost for the pump may be a barrier for adoption by poorer communities. However these costs could be lowered with economies of scale if many pumps are manufactured. For the coil pump to be truly sustainable over time, special care must be taken to fabricate the rotating joint. Daily monitoring of the pump and anchor system for the build-up of river debris must also be performed.

\section{ACKNOWLEDGMENT}

We thank Fr. Michele Crugnola and the residents of Chirundu for their tireless and inspiring efforts. We also thank Fr. Bert Otten, Hannah Rolston, Justin Milne and Steve Szablya for their contributions to the project. 


\section{REFERENCES}

${ }^{1}$ Vörösmarty, C. J., Green, P., Salisbury, J., Lammers, R. B. (2000). Global Water Resources: Vulnerability from Climate Change and Population Growth Science, Vol. 289 no. 5477 pp. 284288

${ }^{2}$ WHO/UNICEF. (2005). Joint Monitoring Programme for Water Supply and Sanitation. Water for life : making it happen. New York.

${ }^{3}$ United Nations. (2006). The $2^{\text {nd }} U N$ World Water Development Report: 'Water, a shared responsibility. New York.

${ }^{4}$ Leslie, A. J., Wallace, K. (2008). Zambezi Crocodile Research Project. University of Stellenbosch; Imperial College of London, Conservation Ecology \& Entomology; Biology. Stellenbosch: Earthwatch Institute, USA.

${ }^{5}$ WHO (2006). Guidelines for Drinking-water Quality First Addendum to Third Edition Volume 1 Recommendations. World Health Organization: Geneva.

${ }^{6}$ Crugnola, Michelle. (2008). Personal communication.

${ }^{7}$ ABS Alaska. (2009). Product Catalog.

http://www.absak.com/catalog/index.php/cPath/33 89 90, Retrieved April 6, 2011.

${ }^{8}$ Fraenkel, P.L. (1986). Water Lifting Devices. Food and Agriculture Organization of the United Nations Irrigation and Drainage Paper 43. Rome. http://www.fao.org/docrep/010/ah810e/ah810e00.htm, Retrieved April 6, 2011.

${ }^{9}$ Global Village Institute for Appropriate Technology. (2011). Hydraulic Ram Pump. http://www.i4at.org/lib2/hydrpump.htm, Retrieved April 6, 2011.

${ }^{10}$ Rees, Abraham (1820). The Cyclopaedia of Arts, Sciences and Literature, Longman, Hurst, Rees, Orme and Brown Publishers. London.

${ }^{11}$ Ewbank, Thomas. 1849. A Description and Historical Account of Hydraulic and Other Machines for Raising Water, Greeley and McElrath Publishers, New York.

${ }^{12}$ Belcher, A. E. (1995). Recovery of Revenues Lost to Fish Passage. Proceedings of the American Society of Civil Engineers International Conference on Hydropower, July 25 - 28, San Francisco.

${ }^{13}$ Ohlemutz, Rudolf E. (1975). "The Hydrostatic Pump and Other Water-lifting Devices in the Context of the Intermediate Technology Approach", Dissertation, University of California, Berkley.

${ }^{14}$ Morgan, Peter R. (1979). "A New Water Pump: Spiral Tube", The Zimbabwe Rhodesia Science News. 13(18):179-180.

${ }^{15}$ Stuckey, A.T., Wilson E. M.(1980). "The Stream-powered Manometric Pump", Proceedings of the Institute of Civil Engineers Conference on Appropriate Technology in Civil Engineering, London, 105-108.

${ }^{16}$ Tailer, Peter. (2005). The Spiral Pump, a High Lift, Slow Turning Pump. http://lurkertech.com/water/pump/tailer/, Retrieved April 6, 2011.

${ }^{17}$ Mortimer, G. H. and Annable, R.(1984). 'The Coil Pump - Theory And Practice', Journal of Hydraulic Research, 22: 1, 9-22.

${ }^{18}$ Kassab, S. Z., Abdel Naby, A. A., Abdel Basier, E. (2005). Coil Pump Performance Under Variable Operating Conditions. Ninth International Water Technology Conference, IWTC9 2005, Sharm El-Sheikh, Egypt, 655-672. 
International Journal for Service Learning in Engineering Vol. 6, No. 1, pp. 33-45, Spring 2011

ISSN 1555-9033

${ }^{19}$ Reysa, G. (2005). Building an Undershot Waterwheel

http://www.builditsolar.com/Projects/Hydro/UnderShot/WaterWheel.htm, Retrieved April 6, 2011. 